\title{
EXPERIMENTAL STUDY OF AGGLOMERATION OF GRASS PELLETS IN FLUIDIZED BED GASIFICATION
}

\author{
NORA C. I. S. FURUVIK, RAJAN JAISWAL \& BRITT M. E. MOLDESTAD \\ Department of Process, Energy and Environmental Technology, Faculty of Technology, \\ Natural Science and Maritime Science, University of South-Eastern Norway, Norway
}

\begin{abstract}
The agglomeration tendency during gasification of grass pellets in a bubbling fluidized bed reactor was studied. Particle agglomeration occurs as a consequence of interactions between the bed particles and the biomass ash during the thermal conversion of biomass in fluidized beds. The continuous operation and high efficiency of the fluidized beds are in these cases limited by partial or complete de-fluidization. In order to study the agglomeration tendency of grass pellets at defined operating conditions, controlled agglomerations tests are performed in a laboratory scaled $20 \mathrm{~kW}$ bubbling fluidized bed reactor. The effect of the ratio between the superficial fluidization velocity $\left(\mathrm{u}_{0}\right)$ and the minimum fluidization velocity $\left(\mathrm{u}_{\mathrm{mf}}\right)$ on the agglomeration tendency for grass pellets is reported. The results show that agglomeration in the bed can be recognized by fluid dynamic disturbances in the bed, and if not counteracted, de-fluidization will occur. The ratio $\mathrm{u}_{0} / \mathrm{u}_{\mathrm{mf}}$ influences the agglomeration tendency and the de-fluidization of bed. As the ratio $\mathrm{u}_{0} / \mathrm{u}_{\mathrm{mf}}$ increases, the agglomeration tendency and the de-fluidization time decreases. The de-fluidization temperature was not influenced by the changes in the superficial velocity ratio.

Keywords: biomass fluidized bed gasification, particle agglomeration, de-fluidization.
\end{abstract}

\section{INTRODUCTION}

The massive expansion in the use of fossil fuels and the world-rising fear over the effects of climate changes, have brought to light the search for a renewable and climate-friendly alternative to fossil fuels [1]. Among the different sustainable energy conversion technologies, fluidized bed biomass gasification is considered a promising contribution to the shift towards renewable energy production. Fluidized beds offer homogenous operation conditions and excellent fuel/gas contact, and are therefore ideally suited for converting biomass into an energy-rich synthetic gas. The produced gas has several applications, and can be used either directly for production of heat and power or it can be further processed into biofuels and other conventional chemicals [2].

Despite the many advantages with fluidized bed biomass gasification, the process introduces ash-related challenges that are the main drawback for the commercial breakthrough [3]. These problems are generally associated with molten biomass ash that interacts with the bed materials, forming agglomerates that create fluid dynamic disturbances in the bed. Particle agglomeration is a key concern in fluidized bed biomass gasification. The presence of agglomerates results in instabilities with bubbling and channeling in the bed, which changes the fluidization character of the particles and makes further fluidization impossible [4]. The phenomenon may further cause decreased heat transfer and local temperature deviations followed by de-fluidized volumes in the bed [4]. De-fluidization is described as a total collapse of the fluidized bed, and can be recognized as rapidly decreasing pressure and substantial temperature changes during the gasification process. In the most severe cases, particle agglomeration transforms the fluidized bed into fixed bed conditions and may lead to unscheduled shutdowns of the whole installation [1]. Fig. 1 pictures a photo of biomass ash particles melted together with bed material that are grown to a larger agglomerate in a bubbling fluidized bed reactor. 


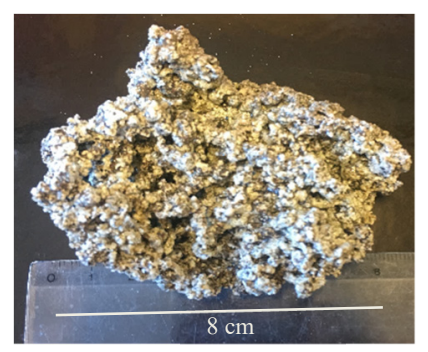

Figure 1: Agglomerates from biomass ash and silica sand particles.

Particle agglomeration during gasification of biomass in fluidized beds typically originates from certain ash-forming elements, which are released from the biomass during the heating process. The most significant ash-forming elements in biomass are silica $(\mathrm{Si})$, potassium $(\mathrm{K})$, calcium $(\mathrm{Ca})$, magnesium $(\mathrm{Mg})$, aluminium $(\mathrm{Al})$, phosphor $(\mathrm{P})$, chlorine $(\mathrm{Cl})$, sodium $(\mathrm{Na})$ and sulphur $(\mathrm{S})$ [2]. The tendency of particles to agglomerate is highly coupled to the physical characteristics and the high temperature chemistry of the biomass ash. Melting processes and chemical reactions produce an alkali liquid phase that can form a bridge between the ash and bed particles [5]. With increased bed temperatures, the viscosity of the liquid phase will decrease and cause larger adhesive forces that glue the particles together. The agglomeration process is initiated by ash deposition and formation of a coating layer on the surface of the bed particles, and is dominated by a combination of the three mechanisms illustrated in Fig. 2 [5]. First, the transfer of solid ash particles onto the surface of the bed material (here: Silica sand, $\mathrm{SiO}_{2}$ ) through van der Waals forces. The second mechanism is the condensation of volatilized ash on the bed particles, while the third mechanism is the attachment of molten or partially molten ash to the surface of the bed particles due to chemical reactions between the gaseous alkali components and the particles (solid ash + bed material) [5].

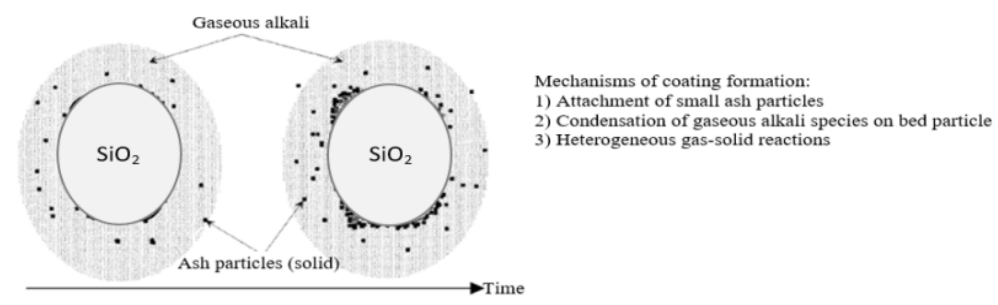

Figure 2: Deposition of biomass ash on the bed particles.

The ash melting and following agglomeration process depends on the ash characteristics, and can also be influenced by the bed operation conditions or the nature of the bed material [2]. In most ash-layer coatings, $\mathrm{Si}$ is the dominating element [5]. The agglomeration process happens as $\mathrm{Si}$ combines with other alkali ash components to form low-melting silicates (eutectics), which are characterized by lower melting points that the individual components [6]. The attachment of ash on the bed particles surface, and the subsequently growth of agglomerates can follow two main routes: Melting-induced or coating-induced agglomeration. Most dominant among the mechanisms is the coating-induced agglomeration, 
where the biomass ash attaches to the surface of the bed particles resulting in formation of an ash-layer enriched in alkali metals. This coating tends to soften and will become sticky at high temperatures, and thereby cause particles to agglomerate due to repeated collisions between the sticky ash-coated particles. In some cases, especially with fuels that are rich in $\mathrm{Si}$ and $\mathrm{K}$, melting-induced agglomeration can occur. The melting-induced agglomeration is a result of direct adhesion of the bed particles due to alkali ash compounds that melt and form a liquid phase at conventional gasification temperatures. The molten ash acts as a glue, which forms liquid bridges between the particles and causes agglomeration. In Fig. 3, the two agglomeration mechanisms between bed material particles $\left(\mathrm{SiO}_{2}\right)$ and the biomass ash are illustrated [5], [7].

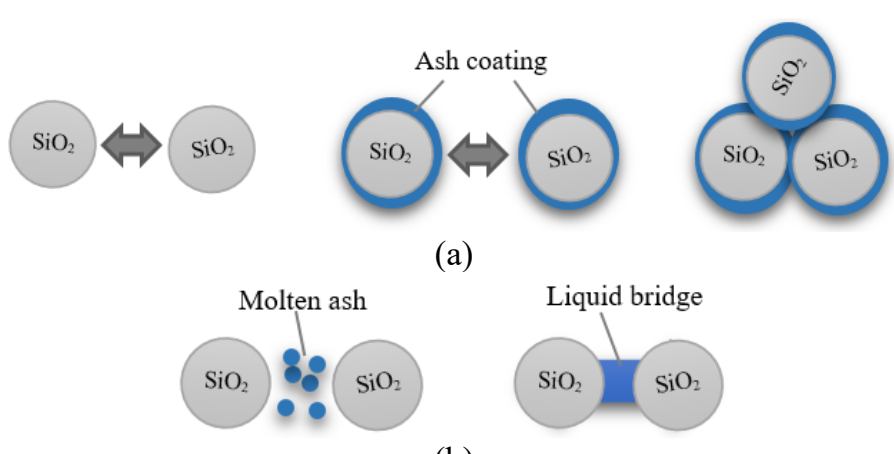

(b)

Figure 3: Coating-induced (a); and melting-induced (b) agglomeration.

This study focuses on agglomeration during gasification of grass pellets in a bubbling fluidized bed reactor. The fuel characteristics indicate that the major ash-forming elements in the investigated grass pellets are $\mathrm{K}, \mathrm{Si}$ and $\mathrm{Ca}$. In addition, the grass pellets are enriched with less amounts of $\mathrm{P}, \mathrm{Na}, \mathrm{Mg}$ and $\mathrm{Al}$. The ash obtained from the grass pellets are composed of various inorganic elements, which are present as oxides dominated by $\mathrm{SiO}_{2}$ and $\mathrm{K}_{2} \mathrm{O}$.

The main objective of this work is to study the agglomeration tendency of grass pellets during a gasification process. The experiments are carried out in a $20 \mathrm{~kW}$ laboratory scale bubbling fluidized bed gasifier under normal bed fluidization conditions. The effect of the ratio of the superficial air velocity over the minimum fluidization velocity $\left(\mathrm{u}_{0} / \mathrm{u}_{\mathrm{mf}}\right)$ in relation to the agglomeration tendency of grass pellets is examined. The operating parameters, i.e. the bed temperature $\left(\mathrm{T}_{\text {bed }}\right)$ and bed pressure drop $\left(\Delta \mathrm{P}_{\text {bed }}\right)$ are continuously monitored throughout the experiments in order to develop data to determine the de-fluidization time $\left(\mathrm{t}_{\mathrm{def}}\right)$ on the onset of de-fluidization.

\section{EXPERIMENTAL SETUP}

The experimental set-up consists of a $20 \mathrm{~kW}$ laboratory scaled bubbling fluidized bed gasifier; the system is divided into seven blocks as illustrated schematically in Fig. 4. The reactor is a stainless steel cylindrical column with inner diameter of $10 \mathrm{~cm}$ and a height of $130 \mathrm{~cm}$. Three electrical heating elements are coiled around the wall of the reactor and are used for external heating of the gasification process. Five thermocouples and five pressure transducers are placed along the height of the column, and are constantly monitoring the operating conditions in the bed. The gasification agent is preheated air, which flows into the reactor through two $10 \mathrm{~mm}$ steel pipes that are placed $27.5 \mathrm{~mm}$ from the bottom of the 
column. The mass flow rate of air is controlled with a BROOK air flowmeter operating in the range of $0.48-4.7 \mathrm{~kg} / \mathrm{h}$. The distance between the pressure and temperature sensors are $10 \mathrm{~cm}$, whereas the first sensor is at the same level as the air supply. Each pressure transducer measures the gauge pressure, i.e. the fluid pressure in excess of the atmospheric pressure, in the given position. The biomass fuel is supplied through a screw conveyor and enters the reactor $21.2 \mathrm{~cm}$ above the air inlet. The product gas leaves the reactor from the top and flows through a pipe into the chimney where it is burned directly. Gas samples for use in analytical setup are collected from a gas sampling point installed in the outlet pipe of the reactor.

The temperature and pressure sensors are connected to the LabView software for data acquisition, and the bed conditions are continuously observed from the temperature and pressure measurements. Fig. 5 pictures a screenshot of the control panel.

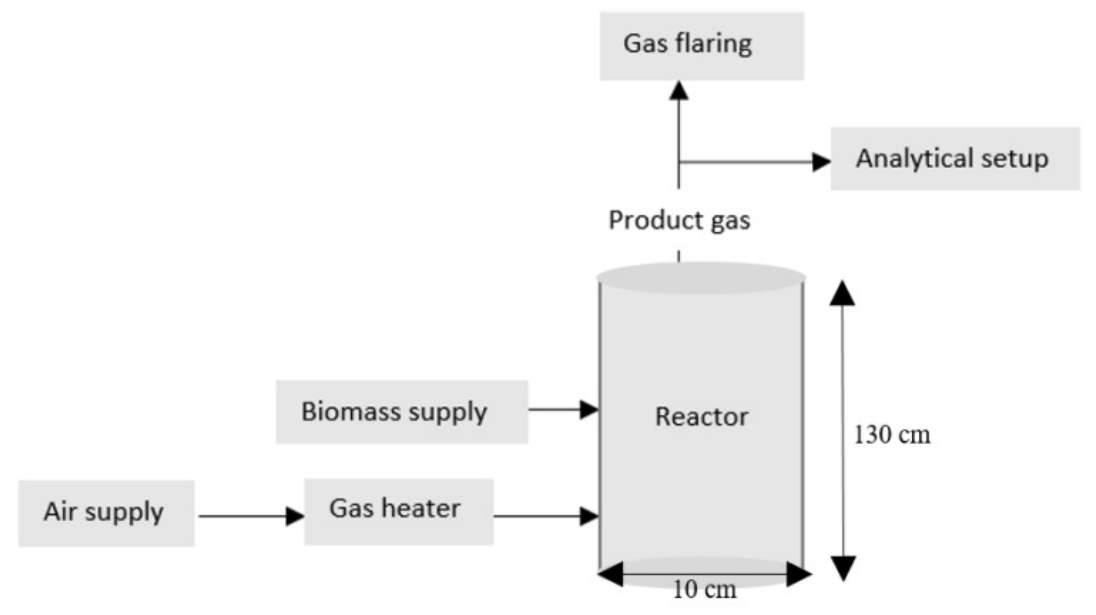

Figure 4: Block diagram of the bubbling fluidized bed gasifier.

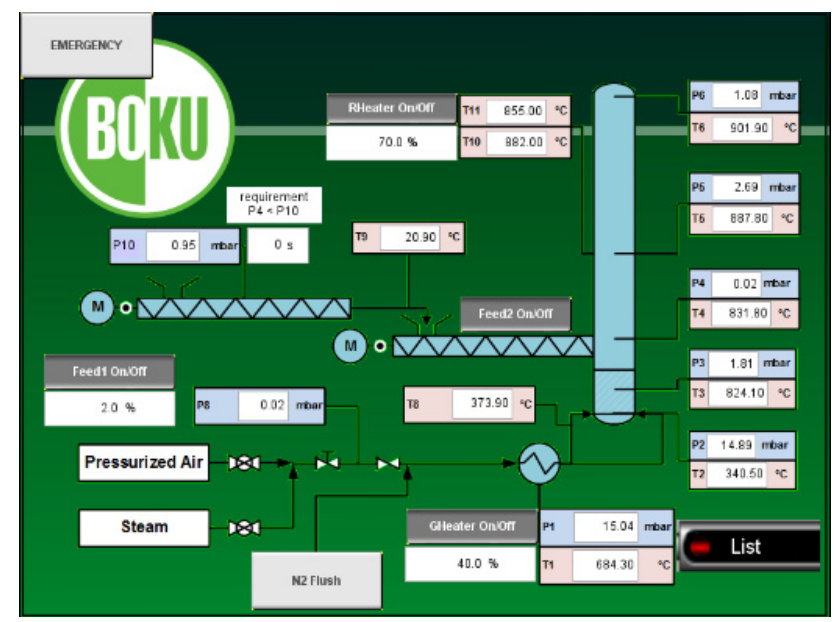

Figure 5: LabView control panel. 


\section{FUEL AND BED MATERIAL CHARACTERISTICS}

Grass pellets sized in the range from $0.5 \mathrm{~cm}$ to $2.0 \mathrm{~cm}$ are used for the agglomeration tests. Prior to the experiments, chemical analyses of the pellets and the ash were carried out by Eurofins Environment Testing Norway AS. The analyses were performed in accordance with the requirements of European Standards SS-EN 14961, SS-EN 15359 and EN 13656. The fuel characterization is presented in Table 1, and the chemical properties of the grass pellets and the ash are listed in Tables 2 and 3, respectively.

Table 1: Ultimate and proximate analyses of grass pellets, dry basis (wt \%).

\begin{tabular}{|c|c|c|c|c|c|c|c|c|c|}
\hline & Ash content & Volatiles & Moisture & Fixed C & $\mathrm{C}$ & $\mathrm{O}$ & $\mathrm{H}$ & $\mathrm{N}$ & $\mathrm{S}$ \\
\hline Fuel & 9.5 & 75.9 & 8.4 & 6.2 & 46.9 & 33.7 & 5.7 & 3.2 & 0.3 \\
\hline
\end{tabular}

Table 2: Major ash-forming elements of grass pellets, dry basis (mg/kg).

\begin{tabular}{|c|c|c|c|c|c|c|c|}
\hline & $\mathrm{K}$ & $\mathrm{Si}$ & $\mathrm{Ca}$ & $\mathrm{P}$ & $\mathrm{Na}$ & $\mathrm{Mg}$ & $\mathrm{Al}$ \\
\hline Fuel & 20,000 & 16,000 & 6,500 & 3,400 & 2,100 & 2,000 & 340 \\
\hline
\end{tabular}

Table 3: Ash composition of grass pellets, dry basis (mg/kg).

\begin{tabular}{|c|c|c|c|c|c|c|c|c|}
\hline & $\mathrm{SiO}_{2}$ & $\mathrm{~K}_{2} \mathrm{O}$ & $\mathrm{CaO}$ & $\mathrm{P}_{2} \mathrm{O}_{5}$ & $\mathrm{MgO}$ & $\mathrm{Na}_{2} \mathrm{O}$ & $\mathrm{Al}_{2} \mathrm{O}_{3}$ & Other \\
\hline Ash & 34,000 & 25,000 & 9,300 & 7,600 & 3,400 & 3,100 & 1,300 & 850 \\
\hline
\end{tabular}

Quartz sand with particle size ranging from $200 \mu \mathrm{m}$ to $425 \mu \mathrm{m}$ was used as bed material. The mean diameter of the particles is $355 \mu \mathrm{m}$, and the particle density is $2,650 \mathrm{~kg} / \mathrm{m}^{3}$. The sand particles are classified as round to angular. Table 4 lists the chemical composition of the bed material.

Table 4: Chemical composition of bed material (wt \%).

\begin{tabular}{|l|c|c|c|c|c|c|c|c|c|}
\hline & $\mathrm{SiO}_{2}$ & $\mathrm{Al}_{2} \mathrm{O}_{3}$ & $\mathrm{~K}_{2} \mathrm{O}$ & $\mathrm{Na}_{2} \mathrm{O}$ & $\mathrm{Fe}_{2} \mathrm{O}_{3}$ & $\mathrm{CaO}$ & $\mathrm{MgO}$ & $\mathrm{TiO}_{2}$ & LOI* \\
\hline Bed material & 83.6 & 7.83 & 2.49 & 2.31 & 1.5 & 1.49 & 0.45 & 0.22 & 0.4 \\
\hline
\end{tabular}
*LOI = Loss of Ignition.

\section{EXPERIMENTAL PROCEDURE}

The bed materials were filled into the bubbling fluidized bed reactor from the top, the mass of the bed particles was 2.0 liters corresponding to a bed height of $20 \mathrm{~cm}$. The agglomeration tests were initiated by loading the grass pellets to the bed with a fuel feed ratio of $2.46 \mathrm{~kg} / \mathrm{h}$. The air mass flow was controlled in the range between $2.0-3.0 \mathrm{~kg} / \mathrm{h}$. The reactor was operated in a controlled gasification range, with bed temperature maintained between $800-900^{\circ} \mathrm{C}$ throughout all experiments. The temperature sensor T3 was used as reference for the bed temperature. Three agglomeration tests were carried out, where the ratio of the superficial air velocity $\left(\mathrm{u}_{0}\right)$ over the minimum fluidization velocity $\left(\mathrm{u}_{\mathrm{mf}}\right)$ varied. Prior to the experiments, the minimum fluidization velocity for the bed particles was calculated to $0.0446 \mathrm{~m} / \mathrm{s}$ from Erguns equation [8]. The bubbling fluidized bed gasifier was operated according to the parameters in Table 5. All three experiments were carried out continuously and separately for approximately 30 minutes, or until the fluidized bed collapsed as a consequence of particle agglomeration. The onset of bed agglomeration was determined by observing 
fluctuations in bed temperature $\left(\mathrm{T}_{\text {bed }}\right)$ and bed pressure drop $\left(\Delta \mathrm{P}_{\text {bed }}\right)$. Agglomerates and the bed material and ash were removed from the gasifier after each test.

Table 5: Operating parameters for the agglomeration tests of grass pellets.

\begin{tabular}{|c|c|c|c|c|c|}
\hline $\begin{array}{c}\text { Air flow rate } \\
(\mathrm{kg} / \mathrm{h})\end{array}$ & $\begin{array}{c}\text { Fuel feed rate } \\
(\mathrm{kg} / \mathrm{h})\end{array}$ & $\mathrm{T}_{\text {bed }}\left({ }^{\circ} \mathrm{C}\right)$ & $\mathrm{u}_{0}(\mathrm{~m} / \mathrm{s})$ & $\mathrm{u}_{\mathrm{mf}}(\mathrm{m} / \mathrm{s})$ & $\mathrm{u}_{0} / \mathrm{u}_{\mathrm{mf}}(-)$ \\
\hline 2.0 & 2.46 & $800-900$ & 0.225 & 0.0446 & 5.0 \\
\hline 2.5 & 2.46 & $800-900$ & 0.281 & 0.0446 & 6.3 \\
\hline 3.0 & 2.46 & $800-900$ & 0.338 & 0.0446 & 7.6 \\
\hline
\end{tabular}

Ash melting behavior from laboratory prepared ash from the grass pellets was determined according to the CEN/TS 15730-1:2006. Generally, the ash melting takes place over a melting range where the solid phase coexists with its liquid phase [2]. The ash melting behavior is useful to make a qualitative statement about the agglomeration tendency of the fuel at given temperatures. The evaluation is done automatically by monitoring a shadow profile of the sample where the changes of the geometry are documented, and the information given from the images defines four characteristic temperatures that are explained in Table 6.

Table 6: Characteristic ash melting temperatures, based on [9].

\begin{tabular}{|l|l|l|l|l|}
\hline $\begin{array}{l}\text { Characteristic } \\
\text { temperature }\end{array}$ & $\begin{array}{c}\text { Shrinking } \\
\text { temperature } \\
\text { (ST) }\end{array}$ & $\begin{array}{l}\text { Deformation } \\
\text { temperature } \\
\text { (DT) }\end{array}$ & $\begin{array}{l}\text { Hemispherical } \\
\text { temperature } \\
\text { (HT) }\end{array}$ & $\begin{array}{c}\text { Flow } \\
\text { temperature } \\
\text { (FT) }\end{array}$ \\
\hline Shadow profile & & & & \\
\hline Description & $\begin{array}{l}\text { Initial } \\
\text { deformation. } \\
\text { First sign of } \\
\text { shrinking. }\end{array}$ & $\begin{array}{l}\text { Spherical } \\
\text { appearance. } \\
\text { First sign of } \\
\text { rounding. }\end{array}$ & $\begin{array}{l}\text { Hemispherical } \\
\text { form. } \\
\text { Half the } \\
\text { original height. }\end{array}$ & $\begin{array}{l}\text { The cylindrical } \\
\text { test piece has } \\
\text { effectively } \\
\text { melted. }\end{array}$ \\
\hline
\end{tabular}

\section{RESULTS}

The influence of the ratio $\mathrm{u}_{0} / \mathrm{u}_{\mathrm{mf}}$ on the de-fluidization time is examined by changing the air flow rate for three controlled bed agglomeration tests. The experimental results are shown in Fig. 6, where the bed temperature $\left(\mathrm{T}_{\text {bed }}\right)$ and bed pressure drop $\left(\Delta \mathrm{P}_{\text {bed }}\right)$ are plotted as a function of time for each of the test runs. De-fluidization can be clearly seen as an unusual decrease in $\Delta \mathrm{P}_{\text {bed }}$ or/and an increase in $\mathrm{T}_{\text {bed. }}$. For the test run where $\mathrm{u}_{0} / \mathrm{u}_{\mathrm{mf}}=5.0$, the gasification process reaches instabilities in the bed parameters after 14 minutes; the drastic fluctuations in $\Delta \mathrm{P}_{\text {bed }}$ and $\mathrm{T}_{\text {bed }}$ suggest the presence of agglomerations in the bed. If not counteracted, the modifications in particle size result in segregation of the bed where the agglomerated particles accumulate and either settle at the bottom or stick to the walls of the reactor. Segregation is indicated by a slow decline in $\Delta \mathrm{P}_{\text {bed }}$ due to formation and build-up of channels in the bed. Channeling creates de-fluidized volumes that act as "hot-spots", which are the cause of a heterogenous temperature profile. Complete de-fluidization finally occurs at 24 minutes and is detected by a sudden decrease in the $\Delta \mathrm{P}_{\text {bed. }}$. For the test run where $\mathrm{u}_{0} / \mathrm{u}_{\mathrm{mf}}=6.3$, the bed parameters are stable with no fluctuations in $\Delta \mathrm{P}_{\text {bed }}$ and homogenous $\mathrm{T}_{\text {bed }}$ during the first 18 minutes of the run. At this time, the temperature profile makes a sudden 
change and shows a significant increase in the temperature gradient, suggesting onset of particle agglomeration in the bed. However, the lack of variation in $\Delta \mathrm{P}_{\text {bed }}$ indicates that only small fractions of the bed particles have been agglomerated. After 30 minutes, no defluidization is observed. When $\mathrm{u}_{0} / \mathrm{u}_{\mathrm{mf}}=7.6$, the bed conditions are recognized by higher $\Delta \mathrm{P}_{\text {bed }}$ and higher $\mathrm{T}_{\text {bed }}$ at the start-up of experiment. $\Delta \mathrm{P}_{\text {bed }}$ shows no fluctuations while $\mathrm{T}_{\text {bed }}$ shows a decreasing temperature profile during the first 8 minutes of the run. At this time, a sharp reduction in $\Delta \mathrm{P}_{\text {bed }}$ occurs at the same time as the bed reaches homogenous $\mathrm{T}_{\text {bed }}$, indicating that agglomerates are refluidized as the $\Delta \mathrm{P}_{\text {bed }}$ drops to a stable value. No disturbances or defluidization were observed during the next 25 minutes of the test run. During normal gasification conditions, $\Delta \mathrm{P}_{\text {bed }}$ is stabilized in the range between 10-15 mbar for all experiments. When de-fluidization occurs, the differential pressure drops drastically with over 10 mbar to below 3 mbar. From the observed bed conditions, it is found that $\mathrm{u}_{0} / \mathrm{u}_{\mathrm{mf}}$ does not influence the de-fluidization temperature $\left(\mathrm{T}_{\mathrm{def}}\right)$. For grass pellets, de-fluidization of the bed was observed when the temperature reached $860^{\circ} \mathrm{C}, \mathrm{T}_{\text {def }}=860^{\circ} \mathrm{C}$.

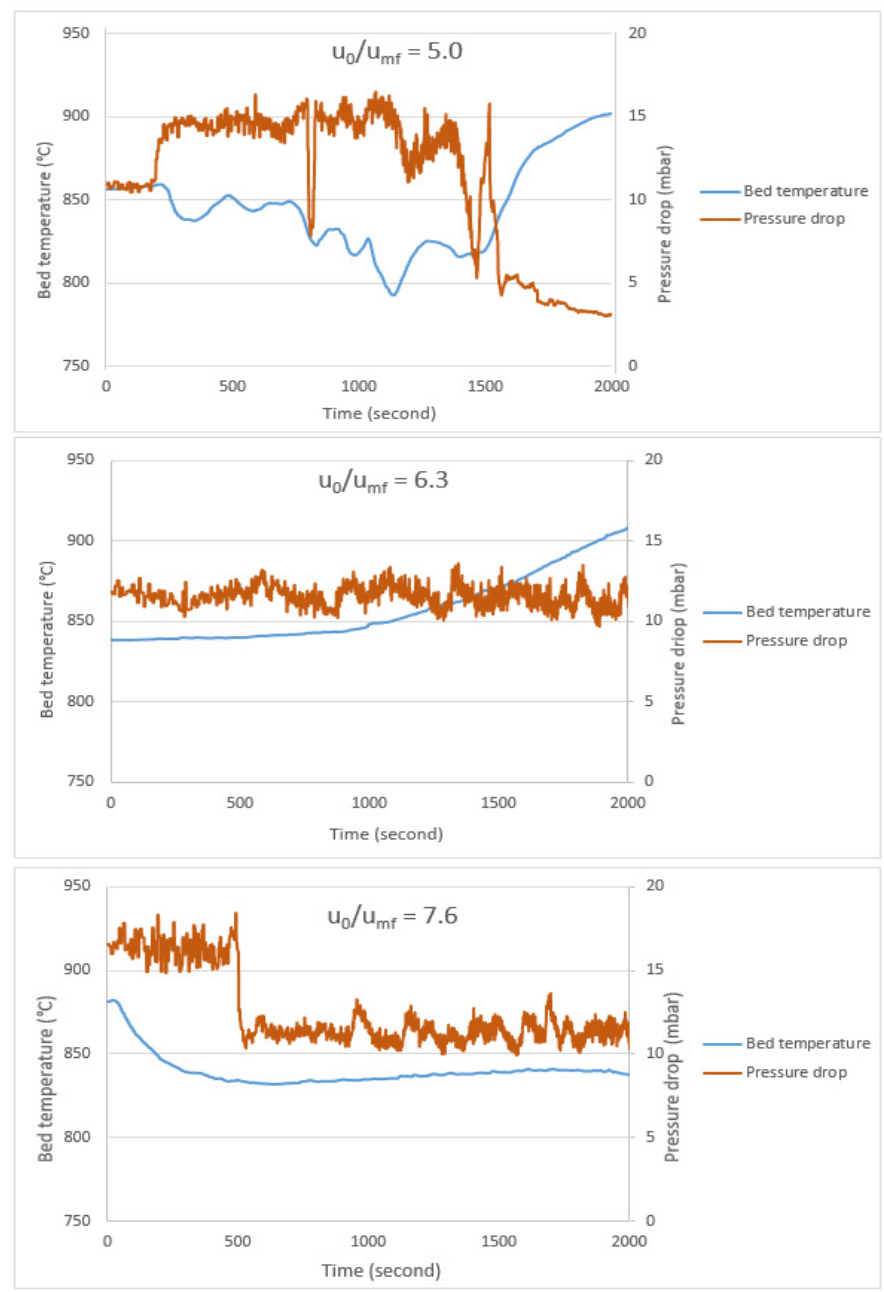

Figure 6: Bed temperatures and pressure versus time for agglomeration tests. 
The results from the agglomeration tests indicate that higher ratio of $\mathrm{u}_{0} / \mathrm{u}_{\mathrm{mf}}$ will decrease the onset of agglomeration and increase the de-fluidization time. Increasing the air superficial velocity gives better mixing of the particles, and may result in breaking of formed agglomerates due to increased forces acting on the particles. Additionally, high fluidization velocity reduces the amount of ash in the bed as some of the ash particles may flow out of the reactor together with the producer gas. Increasing the ratio of $\mathrm{u}_{0} / \mathrm{u}_{\mathrm{mf}}$ can slow the particle agglomeration and prevent de-fluidization. However, upper limits for air mass flow exist during the gasification process; if the amount of air exceeds the stoichiometric amount, the process will go from gasification to combustion.

The observation of the bed material at the end of the agglomeration tests shows presence of agglomerates of various sizes after each of the three experiment. The agglomerates are of distinct types, as pictured in Fig. 7 . For the test with the lowest $\mathrm{u}_{0} / \mathrm{u}_{\mathrm{mf}}$ ratio, the agglomerates are formed as result of melting-induced mechanism. These agglomerates clearly show that the bed particles are melted together by hard bridges, resulting in faster agglomeration due to increased adhesive forces between the particles. If the adhesive forces are equal or exceed the drag forces, de-fluidization appears [10]. Once formed, this type of agglomerates tend to stick to the walls of the reactor, or process equipment, causing increased de-fluidized volumes with temperatures around the agglomerates. For the tests with higher $\mathrm{u}_{0} / \mathrm{u}_{\mathrm{mf}}$ ratio, the agglomerates are closely connected to the coating-induced agglomeration mechanism. The agglomerates show that bed materials coated with ash have clustered together. These agglomerates interfere with the flow behaviour in the bed. However, as long as the bed maintains homogenous $T_{\text {bed }}$ and the fluidization velocity remains high enough to fluidize the particles, these agglomerates will easily break into smaller particles. If not controlled, the agglomerated particles might grow into larger agglomerates that cause de-fluidization.

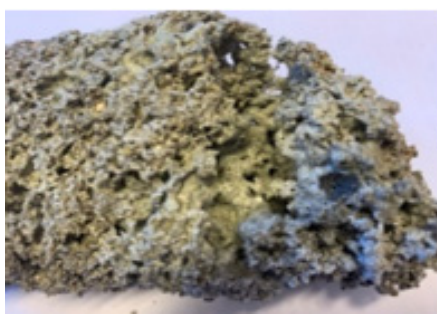

(a)

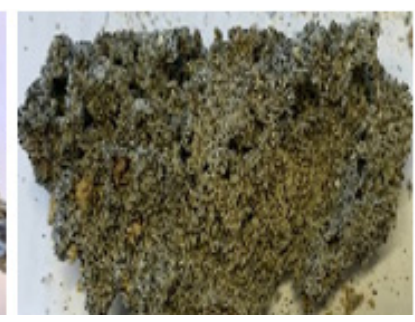

(b)

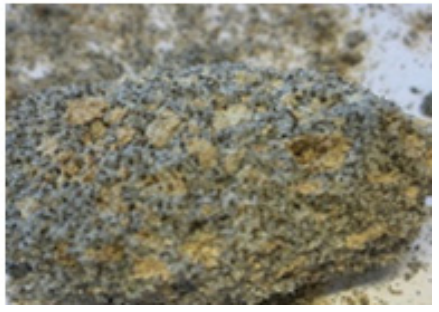

(c)

Figure 7: Agglomerates from grass pellets. (a) $\mathrm{u}_{0} / \mathrm{u}_{\mathrm{mf}}=5.0$; (b) $\mathrm{u}_{0} / \mathrm{u}_{\mathrm{mf}}=6.3$; and (c) $\mathrm{u}_{0} / \mathrm{u}_{\mathrm{mf}}=7.6$.

The particle agglomeration tendency is represented by $\mathrm{T}_{\text {def. }}$. The agglomeration tests indicate that $\mathrm{T}_{\text {def }}=860^{\circ} \mathrm{C}$ for grass pellets, which are far below the characteristic temperatures given by the ash melting analyses shown in Table 7. High $\mathrm{Si}$ and high $\mathrm{K}$ characterize the content of ash-forming elements in grass pellets, and the low $\mathrm{T}_{\mathrm{def}}$ occurs most probably because sticky $\mathrm{K}$-silicates are formed during the thermochemical process.

Table 7: Ash melting behaviour of grass pellets.

\begin{tabular}{|c|c|c|c|c|}
\hline $\mathrm{ST}\left({ }^{\circ} \mathrm{C}\right)$ & $\mathrm{DT}\left({ }^{\circ} \mathrm{C}\right)$ & $\mathrm{HT}\left({ }^{\circ} \mathrm{C}\right)$ & $\mathrm{FT}\left({ }^{\circ} \mathrm{C}\right)$ & $\mathrm{T}_{\operatorname{def}}\left({ }^{\circ} \mathrm{C}\right)$ \\
\hline 1090 & 1150 & 1180 & 1190 & 860 \\
\hline
\end{tabular}




\section{CONCLUSION}

The objective of this work was to study the agglomeration tendency and the related defluidization time in gasification of grass pellets in a bubbling fluidized bed gasifier. The chemical analyses of the grass pellets show that the fuel is rich in $\mathrm{K}$ and $\mathrm{Si}$, and has relatively low content of $\mathrm{Ca}, \mathrm{P}$ and other ash-forming elements. The ash content of the examined grass pellets is $9.5 \mathrm{wt} \%$. In order to develop data to determine the agglomeration tendency of the grass pellets, agglomeration tests were carried out in a laboratory scaled bubbling fluidized bed gasifier. Three different experiments were carried out, at different air mass flow. Defluidized condition in the bed was detected by observation of a sudden decrease in the differential pressure in the bed, or by significant changes in the temperature profile in bed. The de-fluidization temperature for grass pellets was determined to $T_{\text {def }}=860^{\circ} \mathrm{C}$. As the ratio of the superficial air velocity over the minimum fluidization velocity $\left(\mathrm{u}_{0} / \mathrm{u}_{\mathrm{mf}}\right)$ increases, the agglomeration tendency decreases and the de-fluidization time increases. The results indicate $\mathrm{T}_{\text {def }}$ is not affected by the $\mathrm{u}_{0} / \mathrm{u}_{\mathrm{mf}}$ ratio.

\section{ACKNOWLEDGEMENT}

This work is funded by the Research Council of Norway, Program for Energy Research (ENERGIX). Project 280892 FLASH - Prediction of FLow behavior of ASH mixtures for transport biofuels in the circular economy.

\section{REFERENCES}

[1] Öhman, M. \& Nordin, A., The role of kaolin in prevention of bed agglomeration during fluidized bed combustion of biomass fuels. Energy and Fuels, 14(3), pp. 618-624, 2000.

[2] Balland, M. et al., Biomass ash fluidized-bed agglomeration: Hydrodynamic investigations. Waste Biomass Valor, 8, pp. 2823-2841, 2017.

[3] Wang, L., Weller, C.L., Jones, D.D. \& Hanna, M.A., Contemporary issues in thermal gasification of biomass and its application to electricity and fuel production. Biomass and Bioenergy, 32, pp. 573-581, 2008.

[4] Bartles, M., Lin, W., Nijenhuis, J., Kapteijn, F. \& Ommen, R., Agglomeration in fluidized beds at high temperatures: Mechanisms, detection and prevention. Progress in Energy and Combustion Science, 34, pp. 633-666, 2008.

[5] Öhman, M. \& Nordin, A., Bed agglomeration characteristics during fluidized bed combustion of biomass fuels. Energy and Fuels, 14(1), pp. 169-178, 2000.

[6] Visser, S., van Lindt, S. \& Kiel, J., Biomass ash-bed material interactions leading to agglomeration in FBC. Journal of Energy Resource Technology, 2008.

[7] Gatternig, B., Predicting agglomeration in biomass fired fluidized beds. $\mathrm{PhD}$ thesis, Der Technichsen Fakultät der Friedrich-Alexander-Universität Erlangen-Nürnberg, 2015.

[8] Kunii, D. \& Levenspiel, O., Fluidization Engineering, Butterworth-Heinemann: Berlin, p. 69, 1994.

[9] Hesse Instruments, The Heating Microscope and EMII Software, 2016. www.hesseinstruments.de/fileadmin/downloads/Prospekt/BRO_EM301_EN_160608.pdf. Accessed on: 7 Feb. 2020.

[10] Zhong, Y., Gao, J., Guo, Z. \& Wang, Z., Mechanism and prevention of agglomeration/defluidization during fluidized-bed reduction of iron ore. Volodymyr Shatokha, IntechOpen, 2017. DOI: 10:5772/intechopen.68488. 